\title{
RMPICAÇÃO ECONÔMICO-FAMILIAR DECORRENTE DA FLUORETAÇÃO DAS AGUAS DE ABASTECIMENTO PÚBLICO NO RIO GRANDE DO SUL
}

\section{R E A L I Z A C \\ Critro de pesquisas EM ODONTOLOGIA SOCIAL}

\section{Membros:}

Prot. Carlos Reinaldo Mendes Ribeiro Prof. Chefe

Prof. Aluí Oliveira Barbisan

Prof. Fernando Molinos Pires Filho

Prof. Gilberto Ferreira Fossati

Prof. João Antônio Neto Caminha

Prof. Paulo Pereira Louro Filho

Prof. Paulo Soares Edler

Secretárias: Celia Fabbris

Elizabeth Ávila Melo

\section{O R G A N I Z A C A O :}

Prof. Aluí Oliveira Barbisan

Prof. Carlos Reinaldo Mendes Ribeiro

Prof. Gilberto Ferreira Fossati

Prof. João Antônio Neto Caminha

Prof. Paulo Soares Edler

\section{0 - INTRODUÇAO}

Os acontecimentos pré-históricos e históricos da humanidade, constituem, talvez, a prova mais convincente da unidade do gênero humano.

A natureza reflete uma unidade biológica e também a projeção de uma diversidade que se origina da multiplicidade de ambientes físicos e sociais.

Assim é que, o conhecimento médico e odontológico, ao se desenvolverem nesse contexto, constituem uma das expressões mais altas de nossa cultura.

Sendo possivel se distinguir êstes dois aspectos - unidade, diversidade -, temos que todos os fenômenos relacionados com a saúde e a enfermidade nos dão a imagem da unidade biológica do homem, os quais se acham condicionados pela diversidade das instituições sociais e das formas de vida características de cada povo. (5)

Em verdade a institucionalização dos diferentes processos de programação das organizações sociais e do esfôrço conjugado de várias pessoas é que propiciam o desenvolvimento econômico e social da comu- 
nidade. Este, entretanto, sòmente poderá ser alcançado se as peias características do sub-desenvolvimento e da inércia mental de indivíduos estagnados forem rompidas, dando lugar a pensamentos e atitudes que conduzem à plena realização das necessidades da comunidade. (2)

$\mathrm{Na}$ problemática sócio-econômica de comunidades em desenvolvimento, a saúde se constitui em um meio e um fim como elemento componente do bem-estar social.

o setor saúde adquire dimensões novas e a proteção da saúde deixa de ser previlégio de alguns para se tornar direito de todos e responsabilidade direta de muitos.

\section{0 - AS ENFERMIDADES DENTAIS}

A elevada incidência das enfermidades dentais vem consciencializando progressivamente a comunidade, pela destruição da dentadura, tanto de indivíduos adultos como de jovens.

A magnitude do problema assume características desastrosas porque nenhum país da América, desde o Canadá até a Argentina, para falarmos apenas em nosso hemisfério, dispõe de suficiente número de dentistas para tratar estas enfermidades dolorosas e destrutivas.

$\mathrm{Na}$ realidade, tão elevado é o coeficiente de ataque e tão ampla a desproporcionalidade entre necessidade e possibilidade de tratamento, que Experts de todo o mundo, concluíram (9) que a única esperança para solução do problema consiste em aprender e aplicar a PREVENÇÃO.

Das atividades de saúde, a assistência odontológica é a mais dispendiosa, por esta razão é preciso que o assunto seja encarado com objetividade e se busque a forma mais adequada de utilização dos recursos, de maneira a se prestar o maior benefício a um maior número possível de indivíduos.

\section{0 - PROBLEMA Cárie DENTAL}

o problema cárie dental com a evolução da ciência médica, vem assumindo novas proporções na conservação e recuperação da saúde dos indivíduos.

Atualmente, a medicina tem dedicado maiores atenções a geriatria e geriontologia, pela crescente expectativa de vida média de nossas populações.

$\mathrm{Na}$ idade escolar os problemas médicos deixam de ser prioritários em relação à cárie dental, que passa a se constituir em problema de Saúde Pública.

Estudos realizados em Nova Iorque e em Tennessee mostraram que as condições dentárias foram as causas de maior absenteismo ao trabalho. O primeiro estudo foi sôbre as causas de absenteismo, ineficiências e aumento de acidentes entre os empregados do Corning Class Work of Corning, N. Y. e mostrou que a maior percentagem dessas condições, foi determinada mais por causas dentárias do que por doença de ordem médica. (4) 
0 outro estudo realizado por Puffer e Sebelius, em 5.988 trabalhadores da indústria, onde 'foi pesquisado o número de faltas ao serviço por causas dentárias, permitiu verificar um coeficiente anual de 47,3 por 1000 empregados do sexo masculino que perdiam um ou mais dias de trabalho. Para o sexo feminino o coeficiente representava duas vêzes o do sexo masculino. (10)

De observações em trabalhos clínicos desenvolvidos em unidades escolares da Capital pôde constatar-se que a maior causa de falta às aulas eram os problemas determinados pela cárie dental.

As possibilidades de tratamento da cárie dental poderão ser entendidas se tomarmos o exemplo dos Estados Unidos da América do Norte, aonde a solução das necessidades acumuladas requereria 800 milhões de horas de trabalho profissional, ou seja, o equivalente a 74.000 dentistas trabalhando durante 6 anos e que seriam necessários, pelo menos outros 74.000 dentistas para evitar o acúmulo de nôvo atraso.

No Brasil, o problema atinge caracteristicas mais drásticas, pois mesmo considerando-se SòMENTE a população em idade escolar, onde 94\% das crianças têm em média seis (6) dentes para tratar, haveria entre nós mais de 125 milhões de dentes cariados (considera-se em idade escolar primária $22,5 \%$ da população brasileira). Todos os dentistas existentes no país, cêrca de $30 \mathrm{mil}$, precisariam trabalhar 10 meses, em dia de 8 horas, sem respeitar sábado e domingo, para tratar sòmente êsses dentes e sem atender nenhum outro cliente. E, quando terminassem o tratamento, as crianças já teriam outro tanto de dentes cariados.

\section{0 - MINIMIZAC̆̃̃ DO PROBLEMA: FLCOR}

A esperança que nos resta para a solução dêsse problema cárie dental será a adoção de u'a medida coletiva ADEQUADA, que beneficie a tôdas as crianças sem distinção de ordem econômica, social ou educacional, sem esfôrço das mesmas ou de seus pais; EFICIENTE, que diminua a incidência da cárie dental de 60 a $65 \%$; PERENE, que seu efeito perdure durante tôda a vida do indivíduo; SEGURA, que não produza o mínimo de efeito tóxico; PRÁTICA, que o procedimento adotado para seu emprêgo seja similar a de outros produtos semelhantes; ECONôMICA, que seu custo seja insignificante face ao benefício econômico e social recebido pela comunidade.

Esta medida de tanta repercussão é a FLUORETAÇÃO DAS ÁGUAS DE ABASTECIMENTO PÚBLICO.

Com a fluoretação todo $o$ problema de saúde dental e de como resolvê-lo passa a ser da competência dos Cirurgiões-Dentistas e dos Engenheiros Sanitaristas.

O papel do Engenheiro Sanitarista é inegàvelmente de muito maior responsabilidade para o contínuo progresso da fluoretação.

Uma das grandes ironias da história é que a água, elemento indispensável para a vida, foi contaminada em muitas épocas e lugares de 
tal forma que se converteu em um elemento transmissor de enfermidades. Com a descoberta da maneira de limpar e purificar a água mediante aditivos químicos, como o cloro, foi possível evitar-se o mau uso que o homem fêz da água. Em época mais recente, graças ao uso de fluoretos, se obteve um passo a mais no domínio das propriedades biológicas da água como meio de defesa da saúde. (6)

o importante é o uso adequado da água, porque, mesmo se encontrando os fluoretos em estado natural, nem tôdas as estações de tratamento apresentam água com flúor ou em proporções devidas.

\section{0 - HISTóRICO DO FLÚOR}

Os estudos de flúor na água de abastecimento público, como medida de redução da cárie, começou em princípios dêste século quando Frederick McKay, dentista de Colorado Springs, U.S.A. se interessou profundamente por um fato que observou entre seus pacientes, a menor incidência de cárie dental em relação aos seus pacientes de Nova Iorque. Durante os 30 anos seguintes, os estudos de McKay levaram-no a concluir que a única diferença entre as crianças dos dois lugares era a água que ingeriam.

Em julho de 1926, Franck Hannan assinalou que o flúor era o agente causador da imunidade à cárie dental. Outros autores confirmaram o trabalho de Hannan. Isto significa que finalmente o homem havia des- coberto um meio eficaz de prevenir a cárie dental.

Entretanto,'desde a descoberta de Hannan até o primeiro programa de fluoretação da água de abastecimento público passou-se um quarto de século de investigações e experimentações.

o mais significativo dos estudos foi o realizado por Dean e colaboradores de serviço de Saúde Pública dos Estados Unidos, que descobriram que do baixo conteúdo de flúor ao maior conteúdo na água de abastecimento, correspondia menor incidência de cárie dental entre as crianças que bebiam a água fluoretada.

Surgiu, então, a dúvida se a ingestão de flúor teria efeitos adversos nos processos fisiológicos. Novos estudos foram realizados e concluíram que o flúor dissolvido em água potável em quantidades pequenas era inócuo; que $1 \mathrm{mg} / \mathrm{l}$ (um miligrama por litro) é a concentração ótima para o contrôle da cárie e que esta concentração está dentro dos limites de segurança absoluta.

\section{0 - VALOR PREVENTIVO DA FLUORETAÇAO}

Quanto ao valor preventivo da fluoretação, em 1945, Engenheiros Sanitaristas e Dentistas iniciaram experimentos controlados mediante programas de fluoretação da água em Grand Rapids, Michigan, Newburgh, New York e Brandford. Como comparação foram tomadas as cidades de Muskegon, Kingston e Sarnia, que não possuíam flúor na água. Também utilizaram-se cidades que pos- 
suiam flúor natural, como: Aurora e siratford. De imediato se confirmou a eficiência da fluoretação da água como medida de Saúde Pública.

Em 1949, em Grand Rapids a incidência da cárie entre crianças de 5 anos foi de $72 \%$ menor que Muskegon cuja água não fôra fluoretada. Em Aurora, com flúor natural na agua a incidência de cárie dental entre crianças foi similar à de Grand Rapids.

No Brasil, em Baixo Guandu, tam. bém se observou uma redução na incidência de cárie dental após a adição de flúor à água de abastecimento.

No Rio Grande do Sul a primeira cidade a ter água fluoretada foi Taquara e os resultados em têrmos de benefícios estão a dizer da eficiência e da economia da aplicação dos fluoretos nas águas de consumo público.

Em 1951 o Serviço de Saúde Pública dos Estados Unidos deu apoio incondicional à fluoretação das águas de abastecimento como medida preventiva da cárie dental. Essa atitude do Serviço de Saúde Pública dos Estados Unidos foi seguida integralmente por tôdas as organizações do campo odontológico, médico e científico: Associação Médica Americana, Associação Dentária Americana, Academia Americana de Pediatria, Associação Americana de Obras Hidráulicas, Organização Panamericana da Saúde, Federação Dentária Internacional, Comitê de Experts em fluoretação das águas da Organização Mundial da Saúde, Associações Comerciais, Sindicatos, Associações de Pais e Mestres e Associações Docentes. (6)
Atualmente, na vigésima segunda Assembléia Mundial da Saúde, a Delegação do Reino Unido da Grã-Bretanha e Irlanda do Norte apresentou um projeto para a fluoretação das águas em todos os países membros da O. M. S. O projeto recebeu o apoio das seguintes delegações presentes à 22. Assembléia: Argentina, Austrália, BRASIL, Canadá, África Central, Ceilão, Chile, Chipre, Tchecoslováquia, República Federal da Alemanha, França, Irlanda, Irã, Itália, J'amaica, Japão, México, Países Baixos, Nova Zelândia, Noruega, Panamá, Polônia, Rumânia, Serra Leoa, Singapura, Suécia, Suissa, Turquia, Uganda, União de Repúblicas Socialistas Soviéticas, República Árabe Unida, Tanzânia, Estados Unidos da América do Norte, Venezuela e Yugoslávia. (9)

A aceitação pela população em todos os países do mundo tem aumentado progressivamente. Nos Estados Unidos de 6 cidades em 1945, hoje beneficia mais de 50 milhões de pessoas.

A fluoretação das águas de abastecimento está hoje beneficiando milhões de crianças com a redução da incidência da cárie dental. Se as crianças bebem água fluoretada desde que nascem até aos 12 anos de idade, período de formação dos dentes, é seguro que apresentarão uma menor prevalência de cárie em relação às crianças de hoje que não contam com o benefício do flúor.

\section{0 - 0 FLŨOR NO SISTEMA DO TRATAMENTO D'ÁGUA}

$\hat{\mathbf{E}}$ bem verdade, entretanto, que ao 
lado do benefício que possa trazer a fluoretação das águas existem obstáculos de certa magnitude, quais sejam: o sal a ser utilizado que é importado, mas que pode ser eliminado de forma efetiva desde que seja escolhido à fonte mais barata de ion flúor; o outro, a falta de sistemas de abastecimento público de água. Porém, o ritmo atual de progresso que vive nosso país nos dá a visão de que estamos em uma era de expansão contínua e ordenada das áreas que propiciam o desenvolvimento sócio-econômico. Nessas estão incluidas - sistema de abastecimento de água potável, o que dá aos Engenheiros oportunidade de contribuir de forma efetiva na melhoria das condições de saúde do povo brasileiro.

Considerando-se e reconhecendo-se a fluoretação como parte básica e integrante do sistema do tratamento d'água, vê-se que a adição do sal de flúor é econômico e indispensável.

Em vários países a fluoretação constitui um procedimento normal e habitual do tratamento da água. Este procedimento, no dizer do Engenheiro Franz J. Maier, (7) é um procedimento tão generalizado como a cloração e a clarificação da água. No Brasil, desde 1967, a fluoretação foi integrada no processo de tratamento da água através da Lei $\mathrm{n}^{\circ}$ 5.318, de 29/9/67 que instituiu a Política Nacional de Saneamento e criou o Conselho Nacional de Saneamento. (3). Este fato é significativo para todos aquêles que independentemente de sua formação profissional, de suas aspirações sociais e de sua vaidade pessoal, preocupam-se com a aplica- ção de medidas de proteção da saúde o que visa o aumento da expectativa de vjida das populações.

\section{0 - VALOR SOCLAL DA FLUORETAÇ̃̃}

A população do Rio Grande do Sul, segundo as estimativas (11) para outubro de 1969 é de 7.082.340 habitantes, sendo $44,27 \%$, ou seja ... 3.136 .920 , considerada população urbana.

$69,38 \%$ desta população urbana é beneficiada com abastecimento público de água.

Aceitando-se que o flúor beneficie comprovadamente, crianças até 14 anos e que êste benefício se perpetue após esta idade, (1) analisemos o aspecto econômico, apenas no grupo etário de 6 a 12 anos, o que corresponde a 380.878 crianças $(17,50 \%$ da população abastecida com água potável).

Estas crianças tem em média .. $4,05 \%$ dentes permanentes atingidos por cárie, o que nos dá um número de:

1.542.555 dentes atingidos por cárie. Dêste total,

1.054.491 estão cariados $(68,36 \%$ do total atingido)

171.686 estão restaurados $(11,13 \%$ do total atingido)

78.362 estão extraídos $(5,08 \%$ do total atingido)

238.016 estão indicados à extração (15,43\% do total atingido).

Esta situação dá um comprometimento econômico da seguinte ordem: (outubro de 1969). 


\begin{tabular}{|c|c|c|c|}
\hline $\begin{array}{l}\text { Tratamento dentário } \\
\text { recebido por crianças }\end{array}$ & $\begin{array}{l}\text { No de } \\
\text { dentes }\end{array}$ & $\begin{array}{c}\text { Valor } \\
\text { Unit. } \operatorname{Cr} \$\end{array}$ & $\begin{array}{c}\text { TOTAL } \\
\mathbf{C r} \$\end{array}$ \\
\hline
\end{tabular}

\begin{tabular}{|c|c|c|c|}
\hline Dentes extraídos & 78.362 & 10,00 & $783.620,00$ \\
\hline Dentes restaurados & 171.686 & 15,00 & $2.575 .290,00$ \\
\hline
\end{tabular}

TOTAL

$3.358 .910,00$

\begin{tabular}{|c|c|c|c|}
\hline Tratamento necessário & $\begin{array}{l}N^{0} \text { de } \\
\text { dentes }\end{array}$ & $\begin{array}{c}\text { Valor } \\
\text { Unit. Crs }\end{array}$ & $\begin{array}{c}\text { TOTAT } \\
\text { Cr} \$\end{array}$ \\
\hline Restaurações & 1.054 .491 & 15,00 & $15.817 .365,00$ \\
\hline Extrações & 238.016 & 10,00 & $2.380 .160,00$ \\
\hline Reposições & 316.378 & 210,00 & $66.439 .380,00$ \\
\hline
\end{tabular}

O total geral incluindo o tratamento já recebido e o necessário atinge: Cr\$ 87.995.815,00.

Destaque-se que sòmente $3,81 \%$ das necessidades em têrmos econômicos são atendidas, o que configura a impossibilidade econômica de ser obtida solução para o problema odontológico, e isto sòmente com referência à cárie dental em dentes permanentes de crianças de 6 a 12 anos de idade.

Considerando-se que o flúor reduz em $60 \%$ o problema de cárie, teríamos tido uma economia de: $\mathrm{Cr} \$$ 52.797.489,00, caso a Lei $\mathrm{n}^{\circ} 3.125 \mathrm{de}$ 18/6/57 tivesse sido cumprida.

Considerando-se, ainda, que por melhor que seja o tratamento odontológico, êste não substituirá a situa- ção de um dente que tenha recebido o benefício do flúor e não tenha sido atingido por cárie.

No Rio Grande do Sul, estima-se a existência de 435.290 famílias abastecidas com água tratada. Distribuindo-se a economia conseguida com a fluoretação (Cr\$ 52.797.489,00) obtem-se por família o valor de: Cr\$121,12. Esta teria sido a economia por família, caso tivesse sido cumprida a Lei e hoje as crianças de 6 a 12 anos recebessem tratamento odontológico de cárie.

\section{0 - VALOR ECONÔMICO DA FLUORETAÇ̃̃}

Vejamos, agora, o quanto teria custado às famílias beneficiadas, a 
adição do flúor à água de abastecimento público.

Tomemos como base a situação de Curitiba que é abastecida com água floretada.

0 custo da adição de flúor por metro cúbico de água tratada foi, em 1968, de $\operatorname{Cr} \$ 0,0012$, incluindo o sal e energia elétrica, considerando-se que não há necessidade de pessoal adicional para operar esta adição.

Aceitando-se os dados do DMAE (8) que estabelece um consumo mínimo de $20 \mathrm{~m}^{3}$ mensais por família, teríamos um custo de $\mathrm{Cr} \$ 0,024$ por família por mês com a adição do flúor.

Isto, ao ano, representa $\mathrm{Cr} \$ 0,288$ e em 12 anos dá um valor total de Cr\$ 3,46 por família.

Considerando-se que com a adição do flúor, a família teria uma economia de $\operatorname{Cr} \$ 121,12$ constata-se que o custo da fluoretação é insignificante face ao benefício econômico recebido.

Destaque-se que o benefício obtido com a fluoretação é compulsório atingindo indiscriminadamente tôdas as classes sociais enquanto que o tratamento dentário, representando sòmente $3,81 \%$ das necessidades é influenciado pela capacidade econômica da família e grau de educação sanitária da mesma.

\section{0 - RESUMO DOS CUSTOS COM A FLUORETAÇÃO}

\begin{tabular}{|c|c|c|}
\hline Custo do flúor por $\mathrm{m}^{3}$ de água $\ldots \ldots \ldots \ldots$ & $\mathrm{Cr} \$$ & 0,0012 \\
\hline Custo do $\mathrm{m}^{3}$ de água (DMAE) $\ldots \ldots \ldots \ldots \ldots$ & $\mathrm{Cr} \$$ & 0,24 \\
\hline $\begin{array}{l}\text { Percentagem que representa o custo do flúor } \\
\text { no custo da água (DMAE) } \ldots \ldots \ldots \ldots \ldots \ldots \ldots\end{array}$ & $0,5 \%$ & \\
\hline Custo do $\mathrm{m}^{3}$ de água (CORSAN) $\ldots \ldots \ldots \ldots$ & $\mathrm{Cr} \$$ & 0,39 \\
\hline $\begin{array}{l}\text { Percentagem que representa o custo do flúor } \\
\text { no custo da água (CORSAN) } \ldots \ldots \ldots \ldots \ldots \ldots \\
\text { Consumo mínimo de água por economia .... }\end{array}$ & $\begin{array}{r}0,3 \% \\
20 \mathrm{~m}^{3}\end{array}$ & \\
\hline Custo por familia/mês $(20 \times 0,0012)$ & $\mathrm{Cr} \$$ & 0,024 \\
\hline Custo por família/ano $(0,024 \times 12) \ldots$ & $\mathrm{Cr} \$$ & 0,288 \\
\hline Custo por pessoa/ano $(0,288: 5)$ & $\mathrm{Cr} \$$ & 0,06 \\
\hline
\end{tabular}

A CORSAN abastece 871.000 pessoas, o que representaria um custo de ................

As hidráulicas municipais abastecem 1.305.405 pessoas o que representaria um custo de ....

Custo total do flúor $\ldots \ldots \ldots \ldots \ldots \ldots \ldots \ldots$ Cr $\$ 130.587,00$ 


\section{0 - CONCLUSÕES}

$1^{\circ}$ - 0 flúor acarretando um aumento do custo de apenas $0,3 \%$ não influencia significantemente na elevação de tarifas.

$2^{\circ}$ - A adição de flúor à água de abastecimento tem de ser u'a medida de rotina como a adição de sulfato de alumínio, cal e cloro, conforme fixa a Lei $\mathrm{n}^{9} 5.318$ de 26/9/67.

$3^{\circ}$ - A fluoretação é tão essencial à saúde da comunidade quanto a cloração e clarificação da água.

\section{2. - REFERENCLAS BIBLIOGRAFICAS}

1 - CHAVEs, P. O. - Cálculo para uma estimativa de benefício obtido com a fluoração das águas no Rio Grande do Sul, após cinco anos. Boletim do Serviço de Odontologia Sanitária. Pôrto Alegre, 1: (1) 2p. jul-set., 1964.

2 - Discurso proferido por ocasião da inauguração das novas instalações da Unidade de Planejamento da Secretaria da Saúde do Rio Grande do Sul. Boletim do Serviço de Odontologia Sanitária. Pôrto Alegre, 5: (3-4) 7-8, mar.-jun., 1969.

3 - COLEÇÃO DE LEIS DE 1967. (Guanabara), Departamento de Imprensa Nacional 5: 23, 1967.

4 - DE CAMP, Howard E. - An Industrial dental health program J.A.D.A. Washington. 49: 213-214, 1954.

5 - DUBOS, Rene - El Hombre y su ambiente. Boletin de la Oficina Sanitária Panamericana. Washington. 59: 471-480, 1965.

6 - GALAGAN, Donald I. - La Fluoruracion del agua como medida de salud pública. Boletin de la Oficina Sanitária Panamericana, Washington, 59: 201-207, 1965.

7 - MAIER, Franz I. - Aspectos de ingenieria de la fluoruracion del agua. Boletin de la Oficina Sanitária Panamericana, Washington. 59: 208-211, 1965 .

8 - MAYER, Lauro A. - Informações sôbre o abastecimento d’água em Pôrto Alegre. Departamento Municipal de Águas e Esgotos. Pôrto Alegre, 1967. 
9 - NOTfCIAS IMPORTANTES SôBRE FLUORIZACIÓN - La Asembleia Mundial de la Salud confirma la fluorización. News Letter de la Federación Dentaria Internacional, $n^{\circ}$ 68, out. 1969.

10 - PUFFER, Ruth R. \& SEBELIUS, Carl L. - Absenteeism in Tennessee industrial plants caused by diseases of the teeth and gum. J.A.D.A., Washington. 33: 1122-1131, 1946.

11 - WAGNER, Édgar M. - Nôvo método de estimativa de população. Pôrto Alegre. Serviço de Estatística da Unidade de Planejamento da Secretaria da Saúde. 1969. 